\title{
Apple Inc. Strategic Marketing Analysis and Evaluation
}

\author{
Xuanyi Chen ${ }^{1, *, a,{ }^{\dagger}}$ Yiran Liu ${ }^{2, *, b,{ }^{\dagger}}$ Hanzhen Gong ${ }^{3, *, c,{ }^{\dagger}}$
}

\author{
${ }^{I}$ Department of Computer Science, North Carolina State University, Raleigh, NC,27695 the United States) \\ ${ }^{2}$ Department of Art and Science, Bentley University, Waltham, MA,02452 The United States \\ ${ }^{3}$ School of Engineering and Informatics, University of Sussex,Brighton, East Sussex, BN1 9RHthe United Kingdom \\ ${ }^{*}$ Corresponding author.Email: ${ }^{a} x c h e n 47 @ n c s u . e d u,{ }^{\mathrm{b}}$ liu_yira@bentley.edu, ${ }^{\mathrm{c}}$ hg319@sussex.ac.uk \\ These authors contributed equally.
}

\begin{abstract}
Apple Inc is an innovative multinational company in the world, which has revolutionized and facilitated the development of the personal electronics devices and the media industries. This case study essentially generated a comprehensive analysis on the current marketing situation of the multinational technology company, Apple Inc, and provided strategic marketing plans recommendation for its future development. Besides, it was carried out through data analysis and a considerable number of secondary literature collection. Our team used PEST (political, economic, social, and technological) analysis and SWOT (strengths, weaknesses, opportunities, and threats) analysis to demonstrate the strengths and challenges of Apple Inc, which were formulated by its related development characteristics and current marketing environment, including political, economic, social, and technological factors. In order to provide specific marketing recommendations, our team did a detailed financial analysis on the product categories and geographical basis.
\end{abstract}

Keywords: Apple Inc., Analysis, Marketing Strategy, Opportunity

\section{INTRODUCTION}

Apple Inc, founded in California on Jan. 3, 1977 as Apple Computer, Inc, with its present name adopted on Jan. 11, 2007, is a technological company that primarily operates in the computer hardware industry, and its primary SIC is radio \& TV communications equipment. Apple launched its first product 'Apple 1 computer' in 1976. Since then, Apple has grown exponentially in terms of products and services. Today, one of the most successful products of Apple is the 'iPhone'. In the fiscal year 2020, iPhone sales of $\$ 137$ Billion represented half $(50 \%)$ of apple's overall revenue of $\$ 274$ Billion. Apple is benefiting from continued momentum in the Services segment, driven by a robust performance of App Store, Apple Music, video, and cloud services. Moreover, demand remains healthy for Apple's product portfolio including iPad, iMac, and Wearables. Apple's short-term prospects are bright, driven by new iPhones that support 5G, revamped iPad and Mac line-up of devices, health-focused Apple Watch 6, and robust growth in the Services business. By looking at a solid balance sheet and strong cash flow statement, Apple's ability to generate profit is above the average level in the industry. However, increasing scrutiny and legal issues have brought impact on the company performance. Following the Yiran Meng's Valuation on Apple Inc [1] and based on the results generated by the valuation models and financial indicators, the recommendation for the customers is to buy or hold shares of Apple. In addition, the author also suggests that the company should consider the increase of dividends when there is a shortage of good investment opportunities.

Analysts of the MarketLine research report [2] believes that Apple's distribution channels, R\&D, and revenue growth are the major strengths of the company, whereas lawsuit and declining profitability remain as concerns. Smartphones market in North America, strategic initiatives, stores expansion, new product launches, and strategic acquisitions are likely to offer growth opportunities for the company. However, foreign exchange risks, intense competition, dependence on network providers, and technological changes could impact its business operations. Faizul Haque [3] in The 
Strategy Watch adds more to the strength aspects of Apple. He believes that the careful selection of employees and strong brand image are also the advantages for Apple. Abhishek Srivastava supported the idea by showing that Apple has been able to be so successful because they've been able to cultivate a following or a tribe who feel special because they have one thing in common [4], that is they all own an Apple product. Apple releases products at an incredibly fast pace and their fans are there on every step of the way to purchase each new product even going as far as camping outside of retail outlets to ensure that they are able to purchase the latest item. With regard to the weakness, Faizul pointed that Apple's higher price than other smart phones cause its decreasing presence in the market for middle-class consumers. The analysts of the Wondershare EdrawMax research report [5] provided a more detailed descriptions on the opportunities of Apple. The major opportunities of Apple are its loyal customers and increase demand for cloud-based services. People who use apple electronics stay loyal to the brand by showing interest in the upcoming devices. With the rise in data connectivity and speeds, more and more people are now utilizing cloud services for their tasks. The market for cloud-based services is growing, and Apple can extend its range of iCloud services and applications. Kiesha Frue [6] showed more on the Threats aspects of Apple by saying that "Imitation has always been a big threat to Apple products. While Apple's design is smooth and simplistic, that is exactly what makes it easy to replicate. Global stores sell fake versions of iPhones and iPod touches which, on the outside, look nearly identical. And many people fall for the scams of "super cheap Apple products sold online."

To create our own idea on the distribution of Apple's products, we researched the product portfolio analysis written by Michael L. Mallin who is a professor in the University of Toledo. Michael introduces the history of the Apple Computer Company and its key product lines, with a financial approach to analyze a company's product portfolio [7]. He also points out that by utilizing a product portfolio analysis, the management team could potentially evaluate the various Apple products to determine which are expected to be the most profitable to the firm in the future. Such an analysis would be important because it would impact the allocation of resources, the amount of cash available to fund other Apple ventures, and signal shareholders the direction of the company. Nik Soh's analysis of Apple gives us a direction on the financial aspect of our research [8]: he analyzes the factors that affect the performance company from the perspective of internal and external factors in Apple Inc to evaluate the company performance. Financial risk, market risk, operating risk, credit risk, and liquidity risk are included in the internal factors. While the external factors comprise the Gross Domestic Product (GDP), inflation, exchange rates, and index rates. For risk factors of Apple Inc, Nur Husnina Mohamad Yusoff from Universities Utara Malaysia says that his analysis shows the factors affecting performances of a company in the perspective of systematic and unsystematic risk and the findings show that the company performances can be influenced by the risk and economic environment [9]. To focus on the geographic basis of Apple's products, Alberto Garcia Marrero [10] points out that Apple Inc, as one of the world's leading multinational enterprises measured by revenue, profits, assets, and brand equity, has been rapid but not linear ascent. it has experienced setbacks along the way. He analyzes Apple's evolution over the past decade and future prospects, with an eye towards identifying opportunities and challenges for global expansion.

In this paper, our group is going to analyze how the Apple's revenue differs from the product categories and geographical basis, as well as why there is a distinguishment between these two types of measurement. Besides the company research, we will also do the PEST analysis and SWOT analysis to have a better overview of Apple's potential profit generating ability. Then we will do the financial analysis for our topic on what is the pattern of Apple's sales revenue that is different in various product category with geographical basis. Finally, we will give our recommendations on how Apple can increase its sales revenue according to different products and in different regions. Also, we will have the evaluation on the analysis we did and the Apple's actual performance to understand the possibility and viability of the recommendations. In the conclusion, we will include insufficiency of the analysis we did and the future outlook of the Apple Inc on its sales performance.

We also believe that the business seasonality is related to the difference in sales revenue. The Company has historically experienced higher net sales in its first quarter compared to other quarters in its fiscal year due in part to seasonal holiday demands. Additionally, new products and service introductions can significantly impact net sales, cost of sales, and operating expenses. The timing of product introductions can also impact the company's net sales to its indirect distribution channels as these channels are filled with new inventory following a product launch, and channel inventory of an older product often declines as the launch of a newer product approaches. Net sales can also be affected when consumers and distributors anticipate a product introduction.

The following parts of the paper are structured as: Section 2 demonstrates the firm background of Apple Inc. Company; Section 3 introduces the PEST Analysis, a way to explore significant external factors which affect the profitability of the Apple company; Section 4 performs a SWOT Analysis which uses diagrams or 
tables to analyze the Apple's risk by focusing on the factors and assessments provided in Section 3, and then provides comprehensive analysis of advantages, disadvantages, opportunities, and threats of Apple, Inc.; Section 5 describes the another new analysis, the Financial Analysis, to provide sales amount of each region and product from the company through Apple's annual financial statements; section 6 provides recommendations for Apple, Inc. to raise profits; Section 7 conducts the evaluations on positive and negative things in this article; Section 8 shows our conclusion based on the above researches and analysis. The last part presents our references.

\section{FIRM BACKGROUND}

Apple Computer, Inc. designs, manufactures, and markets personal computers, software, networking solutions, and peripherals, including a line of portable digital music players. Apple's product family includes the Macintosh line of desktop and notebook computers, the iPod digital music player, the Mac OS X operating system, the iTunes Music Store, the Xserve G5 server, and Xserve RAID storage products. The product brands include iPhone, iPad, Mac, iCloud, Air Pods, Apple TV, Apple Watch, Apple Beats, Home Pod, iPod touch, AppleCare, iPad OS, and MacOS. Apple sells and delivers digital content and applications through Apple Store, App Store, Mac App Store, TV App Store, Watch App Store, and Apple Music. The company's business operations span the US, Europe, the Middle East, and Asia-Pacific. Apple is headquartered in Cupertino, California, the US. The company reported revenues of (US Dollars) US\$274,515 million for the fiscal year ended September 2020 (FY2020), an increase of 5.5\% over FY2019. In FY2020, the company's operating margin was $24.1 \%$, compared to an operating margin of $24.6 \%$ in FY2019. In FY2020, the company recorded a net margin of $20.9 \%$, compared to a net margin of $21.2 \%$ in FY2019.

The markets for the Company's products and services are highly competitive and are characterized by aggressive price competition and resulting downward pressure on gross margins, frequent introduction of new products and services, short product life cycles, evolving industry standards, continual improvement in the product price, and performance characteristics, rapid adoption of technological advancements by competitors, and price sensitivity on the part of consumers and businesses. Many of the Company's competitors seek to compete primarily through aggressive pricing and very low-cost structures, and by emulating the Company's products and infringing on its intellectual property. Here are Apple's major competitors: Acer Incorporated, Alphabet Inc, BlackBerry Ltd, CSG Systems International Inc, Dell Technologies Inc, Fujitsu Limited, HP Inc., International Business, Machines
Corporation, LG Electronics, Inc., Line Corp, Logitech International SA, Microsoft Corp, NetApp Inc, PC Connection Inc, Rogers Communications Inc, Samsung Electronics Co Ltd., Sony Corporation, Synchronoss Technologies Inc, and Toshiba Corporation.

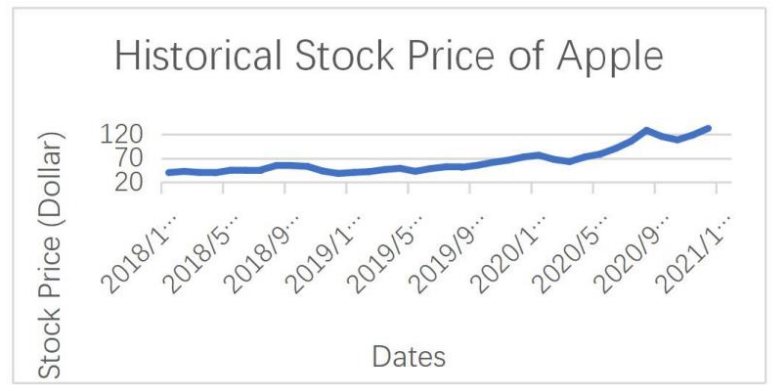

Figure 1 Historical Stock Price

According to Figure 1, the stock price of Apple grows at a relatively stable rate from 2018 to the beginning of 2020. After May 1 in 2020, the stock price experienced a surge which increased from around $\$ 60$ per share to $\$ 134$ per share at the beginning of 2021 . The reason for the stock price surge is mainly because of the emerging of technology stocks such as Tesla. In September 2020, when Apple's announced its newest version of iPhone 12, its stock price reached the peak of the recent three years, which represent the important role of the iPhone in Apple's product portfolio as it generates almost half of apple's annual revenue. Hence, the remainder parts analyze and evaluate the market competitiveness of Apple Inc. through methods of PEST Analysis, SWOT Analysis, and Financial Analysis.

\section{PEST ANALYSIS}

PEST (which stands for political, economic, social, and technological) analysis is a management strategy that is used to understand external factors and evaluate how to adapt to their changing environment. Furthermore, for multinational companies, it is a powerful tool to identify the effects of the external macro events from their perspectives [11].

Table 1. PEST Analysis Matrix

\begin{tabular}{|c|c|}
\hline $\begin{array}{l}\text { Political Factors: } \\
\begin{array}{l}\text { 1. Improving free trade } \\
\text { policies }\end{array} \\
\text { 2. Trade disrupts between } \\
\text { governments }\end{array}$ & $\begin{array}{l}\text { Economic Factors: } \\
\text { 1. Economic recovery } \\
\text { during the COVID } \\
\text { pandemic } \\
\text { 2. The growth of } \\
\text { developing countries }\end{array}$ \\
\hline Socio-cultural Factors: & Technological Factors: \\
\hline $\begin{array}{l}\text { 1. Global remotely } \\
\text { working and studying }\end{array}$ & $\begin{array}{l}\text { 1. The global demand for } \\
\text { cloud computing }\end{array}$ \\
\hline 2. Mounting anti-Apple & 2. Growing technologies of \\
\hline
\end{tabular}




\section{sentiments}

other companies

\subsection{Political factors:}

To begin with, the political related factors affect Apple in both positive and negative ways. The improving free trade policies is an opportunity for Apple to increase its profit. Free trade agreements between countries all over the world are an essential factor to overcome the economic challenges posed by COVID-19. For example, the U.K. government is moving on to new Free Trade Agreements with countries including Australia, New Zealand, and the U.S. It is likely that Apple will be involved in the Free Trade Agreements to distribute even more products around the world.

However, trade disrupts between the U.S. and other countries potentially threaten the growth and the global sales revenue of Apple. For instance, China and the U.S. which are two of the most important markets of Apple are having political tensions for a while. Apple is at a disadvantage if China would set up higher tariffs on imported electric products. As a result, Apple is facing both opportunities and threats in the current political environment.

\subsection{Economic factors:}

Secondly, the world' $\mathrm{s}$ economic factors are essential for Apple as it is a multinational company. With the distribution of vaccines, the world' $\mathrm{s}$ economy is expected to recover faster. The global economy is expected to grow $5.5 \%$ in 2021 and $4.2 \%$ in 2022. The recovery of the economy worldwide is an opportunity for Apple in terms of expansion.

Moreover, the growth rates of developing countries seem more important for Apple. For instance, Apple' s revenue in the Asia Pacific countries was 15,199 million dollars in 2017, while it grew to 19,593 million dollars in 2020. As a result, both global and local economic growth is playing an important role for Apple.

\subsection{Socio-cultural factors:}

Thirdly, Apple' s profitability is affected by sociocultural factors to a great extent. Surprisedly, Apple reported earnings and growth in every segment and geography (the revenue was up 11\%) despite the COVID-19 pandemic in 2020. This is the result of the global remotely working and studying, people need devices to support working, learning, and playing. In particular, MacBook and iPad units are benefiting due to the current social change. Thereby, the rising need for devices is an opportunity for Apple.

However, anti-Apple sentiments are mounting internationally. For example, many Chinese customers are switching to domestic brands as supporting domestic brands, and also, they have lower prices. Hence, external sociocultural factors are influencing the growth of Apple.

\subsection{Technological factors:}

Lastly, the technological factors are generally providing more opportunities for Apple. The global demand for cloud computing is identified as an opportunity for Apple. The company can provide at most 2 TB iCloud storage for individual users. With the development of cloud computing technology, Apple could maximize its profitability in offering cloud services. According to our data, Apple's revenue generated from service grew from 32,700 million dollars in 2017 to 53,768 million dollars in 2020.

Nevertheless, the growing technology of other firms, e.g., Google, is competing with Apple. It could threaten Apple as customers would have more choices in this market.

\section{SWOT ANALYSIS}

SWOT (which stands for strengths, weaknesses, opportunities, and threats) analysis is a significant part of business planning, which using diagrams or tables to analyze a business risk by focusing on these factors and provide assessments. Here is the comprehensive analysis of the strengths, weaknesses, opportunities, and threats of Apple, Inc (Table 2).

Table 2. SWOT Analysis Matrix

\begin{tabular}{|c|c|}
\hline Apple's Strengths: & Apple's Weaknesses: \\
\hline $\begin{array}{l}\text { 1. Brand awareness } \\
\text { and high reputation }\end{array}$ & $\begin{array}{l}\text { 1. High priced } \\
\text { products }\end{array}$ \\
\hline $\begin{array}{l}2 . \quad \text { Top innovative } \\
\text { products and proficient } \\
\text { technology research }\end{array}$ & $\begin{array}{l}2 . \quad \text { Market strategy is } \\
\text { not flexible enough to adapt } \\
\text { to local conditions. }\end{array}$ \\
\hline $\begin{array}{l}3 . \quad \text { Mature and } \\
\text { stable operating system }\end{array}$ & $\begin{array}{l}3 . \quad \text { Incompatibility } \\
\text { with other software }\end{array}$ \\
\hline Apple's Opportunities: & Apple's Threats: \\
\hline $\begin{array}{l}1 . \quad \text { Services business } \\
\text { segment }\end{array}$ & $\begin{array}{l}\text { 1. Coronavirus } \\
\text { epidemic outbreak }\end{array}$ \\
\hline $\begin{array}{l}\text { 2. Smart wearables } \\
\text { technology market increase }\end{array}$ & $\begin{array}{l}2 . \quad \text { The trade war } \\
\text { between China and America }\end{array}$ \\
\hline 3. $\quad$ Self-Driving & 3. Increasing \\
\hline Software Technology & $\begin{array}{l}\text { Competition with other } \\
\text { Tech companies }\end{array}$ \\
\hline
\end{tabular}

\subsection{Apple's Strengths}

To begin with, there are a considerable number of strengths that make Apple achieve success. As for its brand awareness and high reputation, according to Forbes, Apple is the most valuable brand for several years in the world, with a brand value of $\$ 241.2$ billion in 2020. There are also millions of loyal customers 
which number is growing steadily. In addition, Apple has the top innovative products in the world and proficient in technology research and development. Since the founding of Apple, the company always conceives innovative design ideas and generate incredible products which change the world, such as smart technology devices (iPhones, iPads, and Macbooks). From an aesthetic point of view, Apple has the best product design: advanced, stylish, and unique. Amature and stable operating system in their technology devices and personalized computers is also a strength. As for their iPhone OS, it is the second most installed mobile operating system in the world. The simple interface of iOS makes it easy for users to use the device, and it always has excellent performance whenever the user plays games or uses other applications.

\subsection{Apple's Weaknesses:}

Furthermore, it is fact that Apple often priced its products for thousands of dollars. Because of their premium prices of high-end technological devices, Apple' s products always are considered that only the middle or high class to afford. Indeed, the high selling price also because Apple loses potential low-income consumer groups. What is more, limited advertisement is a significant weakness for Apple in comparison to other competitions, such as Samsung technology, Huawei, and Xiaomi. It is obvious that the market strategies of Apple are not flexible enough to local situations in different parts of the world. Under the influence of the media, Chinese citizens will choose more other big brands' products other than Apple's. According to Apple' $s$ financial report, the data indicates there is a decline in sales in China, which is a critical concern for a multinational technology company. Moreover, the incompatibility with other third-party accessories or software is a key issue of Apple, which means Apple users must buy exclusive Apple accessories or applications to keep using their Apple products.

\subsection{Apple's Opportunities:}

With the service industry enters a new era, Apple has provided quantitative digital content and services for their customers, such as iCloud, Apple Music, Apple TV, and iTunes. According to Apple' s financial report, it shows that the proportions of Services have increased from 2017 to 2020. As Apple begins to introduce plenty of new services and push them harder, these services will close contact with the lives of consumers and are gradually becoming the center of attention of consumers. In addition, smart wearable technology will become popular in the world. According to the data from Forbes, the sales of smart devices will upsurge and double in 2022, which will have 233-million-unit sales and create a \$27 billion market share. The combination of the success with Apple smart wearable devices (Apple watch and air pods) and high engagement with users reflects the opportunity for Apple to expand in this field. What is more, autonomous development is extraordinary in the mobile industry. Self-driving software technology is an opportunity for Apple. Instead of building a regular autonomous, Apple could focus on utilizing artificial intelligence research and developing the technology.

\subsection{Apple's Threats}

Nowadays, this is an era of globalization. global intermediate products account for more than half of the total trade volume of goods, and the global supply chain has been closely integrated. The Coronavirus epidemic outbreak is a serious threat for Apple. Inc., a multinational technology company; there will be some disruptions caused by the pandemic. It is a fact that Apple' s supply and manufacturing chains are highly dependent on China. In addition, the tariffs left by the trade war between China and the US will continuously impact the gross margin. Moreover, Apple will confront the increasing aggressive competitions with other large multinationals such as Huawei, Samsung, and Amazon in the future.

\section{FINANCIAL ANALYSIS}

In the financial analysis part, we looked up Apple' $s$ annual financial statements to get the sales amount of each region and product. The quantity distribution chart or the percentage distribution chart is obtained through the bar tool. In table 3, there are the collected data for the Apple revenue by reportable segments on a geographic basis, which includes Americas, Europe, Greater China, Japan, and the Rest of Asia Pacific. In figure 2, a distribution map of the value of sales in the Apple region has been formed, which holds Apple' s Revenue of million dollars in the x-axis, and its related years in the y-axis. Besides, table 4 displays the particularized data of Apple' $s$ net sales by its product category. In figure 3, it presents the bar chart of Apple revenue distributed by reportable segments on the product category. According to these figures and tables, we will analyze the current status and future sales leads for Apple Inc.

Initially, table 3 and figure 2 indicate that Americans are Apple' s largest group of consumers, which account for the highest proportion with 45.2 percentages in 2020. The second large group of consumers is people from Europe and Greater China which contains almost 39.5 percentages of total revenue in 2020; and it is obvious that Apple cannot generate a lot of money from Japan and the rest of Asia Pacific, which holds 14.8 percentages in 2020 . It possibly indicates that the sales 
from different regions are various due to the size of the market of Apple, business competition, and the local population base. To be more specific, the considerable profits generated in America is essential on the grounds that Apple's incredible performance in its home market of the U.S. As the U.S. smartphone market, Apple has the largest share of the market. While international sales account for a burgeoning proportion of Apple's overall revenue, the U.S. continuously contains more than 40 percentages of its net sales. Additionally, there are quantitative Apple stores in the US, with extremely high concentrations. Various smart technology devices and numerous personalized computers, including iPhones, iPads, iMac, and more, will be displayed and sold in their chain of retail stores.

Secondly, in more developed Asian countries such as China and Japan, many high-tech products have also appeared in recent years, such as South Korea' s Samsung phones. Take China as an example, on advertising screens in elevators and on TV shows

Table 3. Apple Revenue by Reportable Segments on a Geographic Basis (dollars in millions):

\begin{tabular}{|c|c|c|c|c|}
\hline & 2017 & 2018 & 2019 & 2020 \\
\hline Americas & 96,600 & 112,093 & 116,914 & 124,556 \\
\hline Europe & 54,938 & 62,420 & 60,288 & 68,640 \\
\hline Greater China & 44,764 & 51,942 & 43,678 & 40,308 \\
\hline Japan & 17,733 & 21,733 & 21,506 & 21,418 \\
\hline $\begin{array}{l}\text { Rest of Asia } \\
\text { Pacific }\end{array}$ & 15,199 & 17,407 & 17,788 & 19,593 \\
\hline Total revenue & 229,234 & 265,595 & 260,174 & 274,515 \\
\hline
\end{tabular}

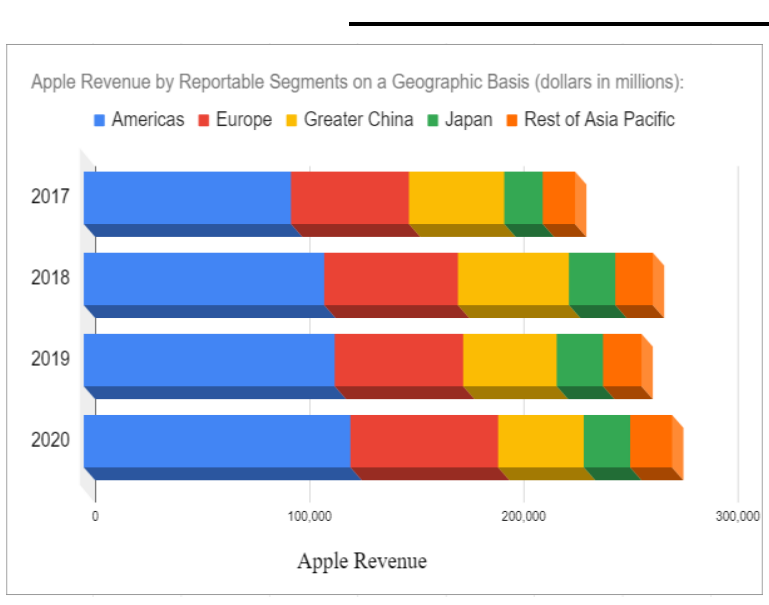

Figure 2 Apple Revenue by Reportable Segments on a Geographic Basis Historical Stock Price watched by family members, the products endorsed by Chinese celebrities usually come from locals. With the media's influence, Chinese citizens can choose other items instead of products from Apple, and this prevents Apple' $s$ sales in a big population country like China to surpass the sales in America. Also, revenue generated from the rest of Asia pacific is quite low might be caused by a low local population base or poor local economic situation. For example, in a country like Africa, where the gap between the rich and the poor is relatively large, local residents may be more concerned about the price of food than buying or using an iPhone; in a country like Japan, in the 2018-2019 year, Japan was reported to be facing new serious aging or low newborn rate situation. These problems indicate that the increase in the number of young people who tend to buy high-tech in Japan is decreasing, which may also affect the development of high-tech companies like Apple.

Compared with quantitative analysis of sales and revenues, this report later focused on the percentage of which product was sold better. According to figure 3, what we expected was that the iPhone was the best product Apple sold, but what surprised the result in the research was that the second-best product sold was Service. Apple's most profitable product, the iPhone, originally released in 2007, has become the company's most successful. The iPhone constantly accounts for around 50 percent of Apple's total sales. Undoubtedly, the iPhone is representative of innovative products in Apple Inc. Its early generation has revolutionized the industry of mobile phones, which assist to popularize the use of high-tech touch-screen smartphones. Recently, in its 14th generation, the new iPhone 12 series launch, helping to drive iPhone sales growth yearover-year amid the COVID-19 pandemic. But it is worth 
noting that, as can be seen in Figure 3, over time, the proportion of iPhone has gradually dropped from $60.8 \%$ to $50.2 \%$, which is a $2 \%$ difference from the peak value in 2018 .

While the proportions of Mac, iPad, wearables, and home accessories are nearly holding constant, the proportions of Services have increased from 2017 to 2020. There is enough evidence to show that Apple' s services such as iCloud and Apple Music are gradually becoming the center of attention of consumers. Compared with the services, the iPhone can no longer maintain old customers or attract more new ones with its new appearance. That is to say, if there are more new inventions like iCloud that can be achieved and used to Apple' s products to serve customers better, Apple will get more benefits.

Table 4. Apple Revenue by Reportable Segments on the Product Category (dollars in millions):

\begin{tabular}{llllll}
\hline \multicolumn{2}{l}{2017} & 2018 & 2019 & 2020 \\
\hline iPhone & 139,337 & 164,888 & 142,381 & 137,781 \\
Mac & & & & \\
iPad & 25,569 & 25,198 & 25,740 & 28,622 \\
Wearables, Home and Accessories & 12,826 & 17,381 & 24,482 & 30,620 \\
Services & 18,802 & 18,380 & 21,280 & 23,724 \\
Total revenue & 32,700 & 39,748 & 46,291 & 53,768 \\
& & & & \\
\hline
\end{tabular}

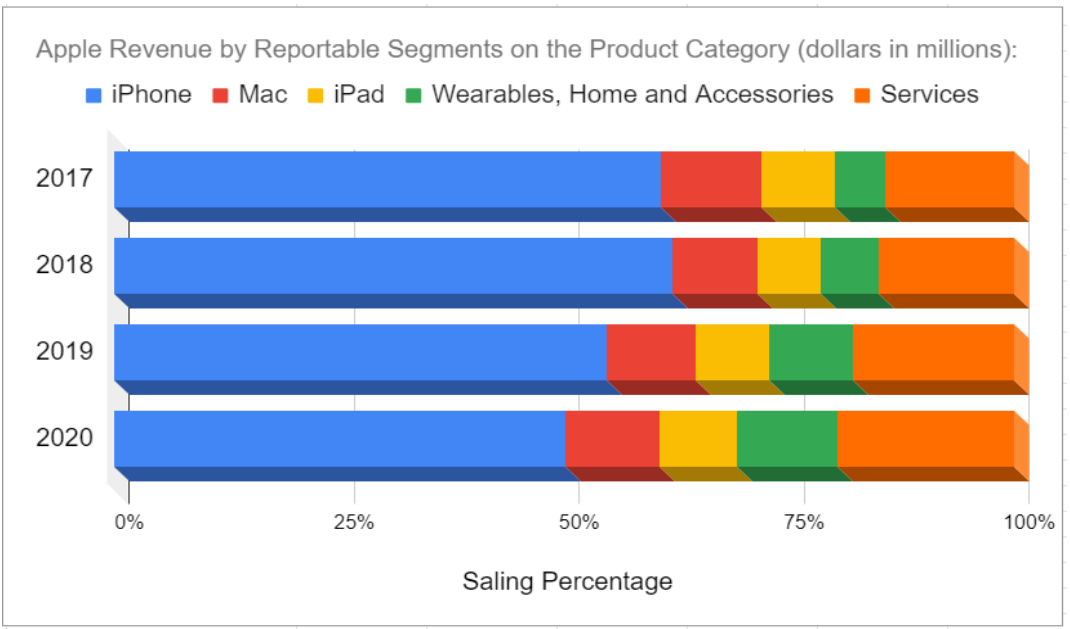

Figure 3 Apple Revenue by Reportable Segments on the Product Category Historical Stock Price

This financial analysis is focused on Apple Inc' $s$ contemporary corporate marketing situation according to the market fields of Apple, which contains the parts of product category and geographic basis of markets. It is lucid to draw the conclusion that Americans is the lucrative market for Apple, and iPhone is the most profitable product. Additionally, there are plenty of opportunities for Apple Inc to upsurge its profit in market regions like China, and Japan, by increasing the investment in advertising. Furthermore, there is a continuously growing trend in the Apple Services area. It is significant for Apple Inc to foresee that and seize the opportunity to increase its market share and revenue.

\section{RECOMMENDATION}

This essay is to suggest Apple consider more local culture in developing countries as the expansion in developing countries is significant. In particular, mask culture, which is a socio-cultural factor, should be considered in China' s market which is one of the most 
important markets. Chinese people wear a mask to prevent the effect of air pollution and COVID-19, and that leads to a technical issue - the current Face ID does not work when people put their mask on. It could be an opportunity to develop iris recognition (technological factor) on iPhone to increase revenue. In addition to that, Apple could develop more wearable, home, and accessories products to compete with the competitors, for example, Google is developing many home accessories.

\section{EVALUATION}

The strengths and weaknesses of this essay are evaluated below.

\subsection{Strengths:}

Methodology: To suggest practical solutions for Apple to increase profit, PEST analysis and SWOT analysis are used, and the data of revenue generated by geographical basis and product category is collected, visualized, and analyzed.

Research sources: A lot of academic journals and professional websites were referenced in our investigation that makes this report reliable and accurate.

\subsection{Weaknesses:}

More research is needed on target customers and markets to investigate responses from them. Any changes should communicate with the community of customers ahead to avoid complaints, and any changes should be aimed to meet customers' wants and needs.

More analysis on technology and investment is needed to analyze the feasibilities of implementing iris recognition on Apple products and developing more home accessory products. Technology and investment are the two essential factors that decide if Apple could make these changes.

\section{CONCLUSION}

With the rapid development of science and technology, a variety of electronic products continue to emerge, and the competition among electronic products in the market is becoming progressively fierce. In this paper, our team conducted SWOT analysis, PEST analysis, and financial analysis to investigate the strengths and drawbacks of Apple' s current status and its marketing strategy, as well as the opportunities and challenges in its future advancement.

As for SWOT analysis, Apple has plenty of competitive advantages, including its brand awareness, preeminent innovative research, and sophisticated operating system. Indeed, it also contains several weaknesses, which include high selling price, limited advertising marketing strategy, and incompatibility with other third-party software. It is important for the company to use its rapid innovation processes to exploit opportunities in different fields, for instance, green energy and self-driving technology. Admittedly, there are also some threats that Apple needs to confront, such as the Coronavirus epidemic, tough competitions between other big brands, and the impact of the trade war. Besides, in this article, our team did the PEST analysis to evaluate the risk for Apple. Political-related factors had both a positive and a negative impact on Apple. For instance, Apple could obtain advantages by the free trade policies, while the company confronts the problems from trade disrupts. For the economic factors, with the distribution of vaccines, the recovery of the world' s economy is essential for the expansion of Apple. Additionally, Apple's profitability is significantly influenced by sociocultural factors. The technological factor in general presents a considerable number of opportunities for Apple, which allows the company to innovate and introduce more effective services and products. In financial analysis, by analyzing Apple' s annual sales and proportions for each product, the article shows decent reasons for having America as Apple' s best market and the iPhone as its bestselling product. In addition, since the proportion of Apple service segment in the annual revenue has continuously expanded, Apple will further increase concentration on that part.

It is challenging for this paper to indicate the rate of return of these recommendations. The particular reasons for the circumstance are this report does not take account of the costs and the required technologies to implement the new technology on Apple products and developing Apple home accessory products, as well as the investigation of customers, reactions to these changes. As a result, for the further study, analysis on the costs of implementing these changes will be carried out and questionnaires will be carried out to investigate the target customers' reactions.

\section{REFERENCES}

[1] YIRAN, Meng - Valuation of Apple Inc.Ser: ISCTE-IUL, 2017. www:<http://hdl.handle.net/10071/14630>.

[2] MarketLine Report, Apple's Company Report, March 2021, 63-66, apple/.

[3] Haque, F., Andrew, R., \&amp; The Strategy Watch. (2020, July 8). SWOT Analysis of Apple Inc. The Strategy Watch. https://www.thestrategywatch.com/swot-analysisapple-inc/. 
[4] Srivastava, A. (2018, February 13). THE OPERATIONS OF APPLE INC. IN CHINA: CHALLENGES AND POSSIBLE SOLUTIONS. Blog My Essay Writer.

[5] The SWOT Analysis of Apple: Edraw Max. Edrawsoft (n.d.). https://www.edrawmax.com/article/swot-analysisof-apple.html.

[6] Frue, K., \&amp; About The Author Kiesha FrueKiesha Frue is a freelance writer and editor with a love for health. (2020, September 16). SWOT Analysis Case Study of Apple Inc. PESTLE Analysis. https://pestleanalysis.com/swotanalysis-case-study-of-apple/

[7] Mallin, M. L., \&amp; Finkle, T. A. (2015). Apple Inc.: Product Portfolio Analysis. Apple Inc.: product portfolio analysis. Journal of the International Academy for Case Study.
[8] Soh, N., \&amp; Najhah, N. (2019). An Analysis Of An Explanation Of Apple Inc. MPRA. https://mpra.ub.uni-muenchen.de/id/eprint/97280.

[9] Mohamad Yusoff, Nur Husnina, Determinants of Risks and Performance in Apple Inc. (May 19, 2018). Available at SSRN: https://ssrn.com/abstract=3181705 or http://dx.doi.org/10.2139/ssrn.3181705

[10] Marrero, A. G. (2017). Abstract. In the Rise of Apple Inc: Opportunities and Challenges in the International Marketplace (ISSN:1934-4244, pp. 5-10). introduction, Florida International University.

[11] Sammut - Bonnici, T., \& Galea, D. (2015). PEST analysis. Wiley Encyclopedia of management, 1-1. 